\title{
PD28 - Is other bovid mammals milk tolerated by children who have been submitted to cow's milk oral immunotherapy?
}

\author{
Mònica Piquer Gibert*, Spera Adriana Machinena, Montserrat Alvaro Lozano, Maria Teresa Giner Muñoz, \\ Olga Domínguez Sánchez, Jaime Lozano Blasco, Ana Maria Plaza Martin
}

From 3rd Pediatric Allergy and Asthma Meeting (PAAM)

Athens, Greece. 17-19 October 2013

\section{Introduction}

Caseins cross-reactivity rises up to $90 \%$ between cow's milk (CM) and other bovid milks. There are few studies on tolerance to other mammals milk in patients submitted to cow's milk oral immunotherapy (CMOIT). AIMS: To determine the percentage of patients whom after CMOIT tolerate water buffalo (WB), goat and sheep's milk proteins (MP). To describe immunologic features which can predict allergy.

\section{Methods}

Inclusion criteria: children submitted to CMOIT tolerating $>150$ cc CM daily, more than 1 year in maintenance phase. We evaluated: total IgE, skin prick test (SPT) to CMP, WB, goat and sheep's MP; specific IgE (sIgE) and IgG4 to CMP, goat and sheep's MP. Patients underwent oral food challenge (OFC) to WB, goat and sheep's MP.

\section{Results}

51 children, 28 males, mean age at CMOIT 6.6 years (2.2-14.2) and 9.2 at OFC with WB, goat and sheep's MP. At OFC to WB, goat and sheep's MP: 47, 30 and 32 patients tolerated; 3,7 and 4 non-anaphylactic reaction; 1,12 and 11 anaphylaxis; 0,2 and 4 didn't undergo OFC, respectively. Significant differences between tolerant and non-tolerant in SPT to casein, goat and sheep's MP, and SIgE to CM, casein, goat and sheep's MP were observed. The area under the ROC curve for goat's SIgE relating tolerance was $0.92, \mathrm{p}<0.05$, cut-off point 5.66 KUI/L (89.5\% sensibility-96.3\% specificity); for sheep's sIgE $0.87, \mathrm{p}<0.05$, cut-off point $7.69 \mathrm{KUI} / \mathrm{L}$ (80\% sensibility$86.7 \%$ specificity). CAP inhibition assays (solid phase goat

Hospital Sant Joan de Déu, Barcelona, Spain and sheep, tolerant vs non-tolerant sera pools, CM as inhibitor) without significant differences although in the tolerant pool a greater inhibition is observed.

\section{Conclusions}

$58.8 \%$ of the patients who have undergone CMOIT tolerate other bovid MP. 92.15\% tolerate WBMP. In OFC to goat and sheep's MP $23.95 \%$ have experienced anaphylaxis and only $1.96 \%$ in WBMP OFC. Our cut-off points can predict adverse events.

Published: 28 February 2014

\section{doi:10.1186/2045-7022-4-S1-P28}

Cite this article as: Piquer Gibert et al:: PD28 - Is other bovid mammals milk tolerated by children who have been submitted to cow's milk oral immunotherapy? Clinical and Translational Allergy 2014 4(Suppl 1):P28.

Submit your next manuscript to BioMed Central and take full advantage of:

- Convenient online submission

- Thorough peer review

- No space constraints or color figure charges

- Immediate publication on acceptance

- Inclusion in PubMed, CAS, Scopus and Google Scholar

- Research which is freely available for redistribution

Submit your manuscript at www.biomedcentral.com/submit 